\title{
Laparoscopic Cholecystectomy in a patient with Situs Inversus Totalis
}

\author{
Samail Shahjahan ${ }^{1}$, Anisur Rahman*2 \\ DOI: https://doi.org/10.3329/bccj.v9i1.53057
}

\begin{abstract}
:
There are diagnostic and therapeutic challenges in cases of symptomatic gall bladder disease in patients with situs inversus totalis (SIT), where there is complete reversal of visceral topography in thorax, abdomen or both. The difficulty to treat these patients with conventional laparoscopic cholecystectomy may be more pronounced for right handed surgeon and requires modifications in working ports and their positions. We present a case of laparoscopic cholecystectomy in a patient with SIT, and describe the technical details that enable the safe conclusion of the operation.
\end{abstract}

Keywords: Laparoscopic Cholecystectomy, Situs Inversus totalis(SIT)

\section{Background}

Situs inversus is a rare autosomal recessive disorder in which there is opposite (mirror image) orientation of thoracic or abdominal organs (partial) or both (total). Incidence of such condition occurs to be in 1 in 5000 to 20000 live births ${ }^{1}$.This condition can also associated with a number of conditions, like Kartagener's syndrome (bronchiectasis, sinusitis, situs inversus) and cardiac anomalies, although infrequently ${ }^{2}$.

Laparoscopic cholecystectomy in such patients is challenging due to the position of organs, possible associated anatomical abnormalities and the need to modify the working ports location. A modified laparoscopic operative technique is needed, adding to the unfamiliarity with the procedure, even for an experienced surgeon.

So far only 67 cases of SIT has been reported to undergo laparoscopic cholecystectomy ${ }^{3}$. The conversion rate in these cases was nearly $30 \%$, with longer operating time, but successful removal of the gallbladder was the rule rater than exception. We report our experience with such a case. First Laproscopic Cholecystectomy in a patient with SIT was performed in $1991^{3}$

\section{Case Report}

A 55 years old female, with history of diabetes, hypertension and hypothyroidism presented with intermittent epigastric pain, occasionally radiating to left hypochondriac region and left shoulder for a month. She also complained of occasional

1. Dr. Samail Shahjahan, MBBS, MRCS (England), Speciality Registrar, Cardiac Surgery, Royal Papworth Hospital NHS Foundation Trust, Cambridge, UK

2. Prof. Anisur Rahman, MBBS, MSc (Canada), FCPS (Surgery), FRCS (Glasgow, UK), Senior Consultant, General and Laparoscopic Surgery, United Hospital Limited, Dhaka, Bangladesh

*Corresponding Author:

Prof. Anisur Rahman

E mail : anisur.rahman2@uhlbd.com vomiting, and denied having fever or jaundice. A diagnostic workup included abdominal ultrasonogrphy, revealed left sided contracted gall bladder containing multiple stones. It also showed the liver is on left side and the spleen on right side of abdomen. So a diagnosis of situs inversus with cholelithiasis was made. Lab results ruled out infection (WBC $=13000 /$ cumm, Neutrophil $63 \%$ and Lymphocyte $31.5 \%$ ) or liver function abnormalities. Pre-operative chest $\mathrm{X}$-ray $\mathrm{P} / \mathrm{A}$ view and $2 \mathrm{D}$ Echocardiogram revealed mirror image dextrocardia (Figure 1).

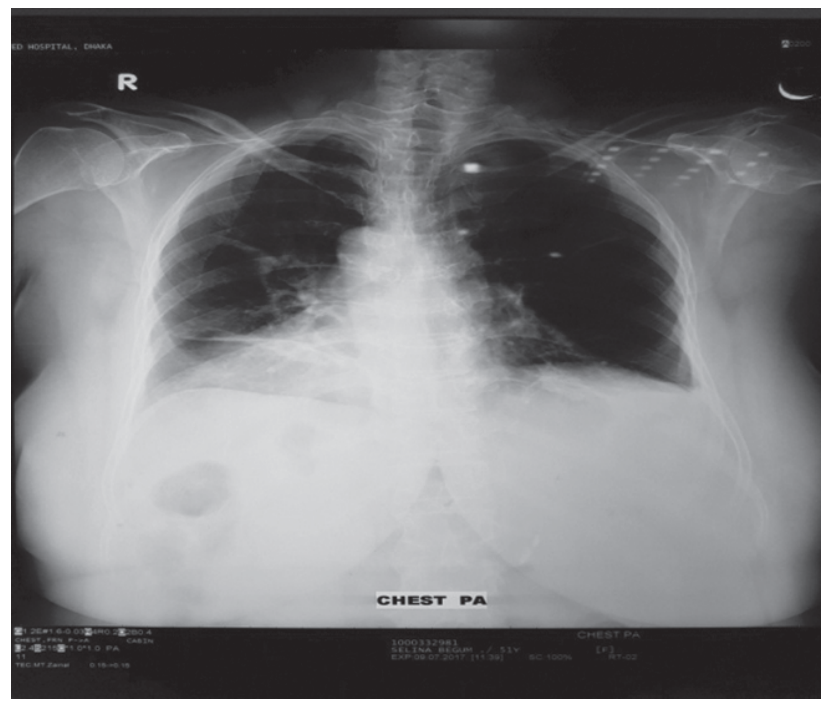

Fig 1 : Chest Xray $\mathrm{P} / \mathrm{A}$ view showing mirror image dextrocardia (Apex on right 5 th intercostal space)

With the diagnosis of biliary colic, laparoscopic Cholecystectomy was performed under General Anesthesia. A $10 \mathrm{~mm}$ umbilical port was made for introduction of $0^{\circ}$ telescope. Another $10 \mathrm{~mm}$ epigastric port was placed which as one of two working ports. Two $5 \mathrm{~mm}$ ports were placed, one at left mid clavicular line $3 \mathrm{~cm}$ below the subcostal line (second working port) and another on $4 \mathrm{~cm}$ below and slightly 
medial to the 3rd port (for gallbladder fundus retraction). Surgeon and assistant stood on the right side of the patient, positioning the patent in reverse Trendelenbeurg and tilted to the right.Upon exploration the liver, Gall Bladder and Caecum with appendix were found on the left side and greater curvature of stomach and spleen on right side (Figure 2). No other congenital abnormalities were found.

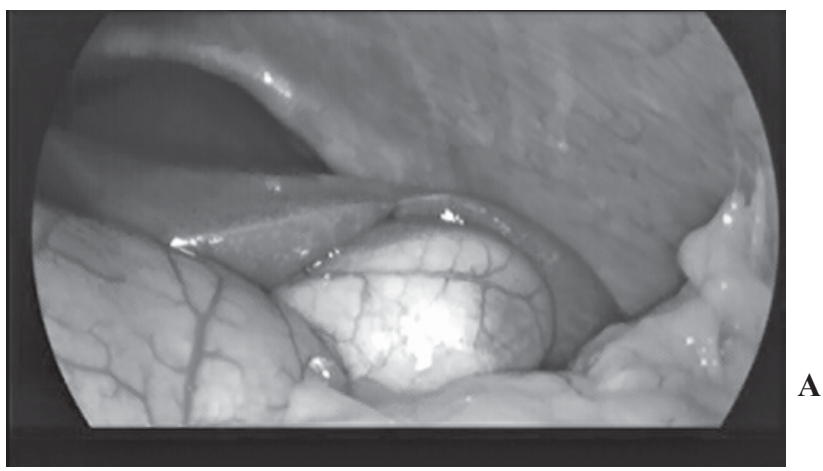

Fig $2 \mathrm{~A}$ : Showing liver and gall bladder in left side of upper abdominal cavity

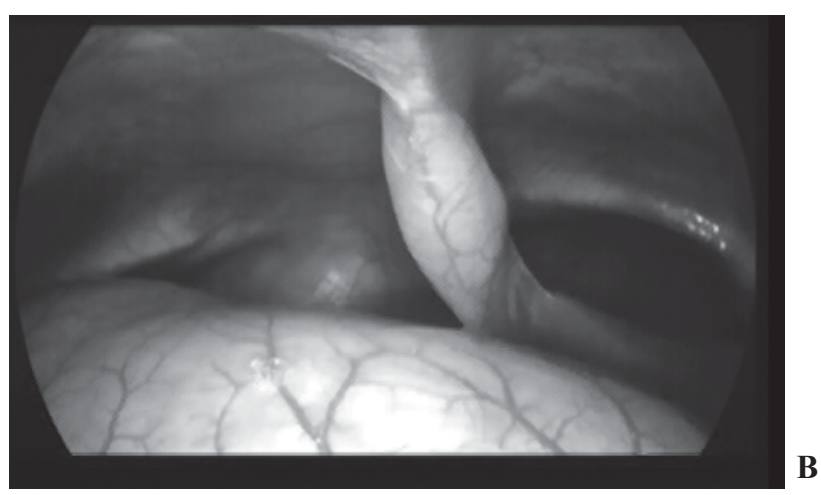

Fig 2 B : Body of stomach on right side with greater curvature directed towards right and inferior border of liver on left side. Falciform ligament in the middle

Hartmann's pouch of the gallbladder was held through the epigastric port and dissection was performed using the left subcostal port; but these positions were switched intermittently to achieve maximal comfort. Clipping of the cystic duct and artery was more convenient through left subcostal port (Figure 3), due to right-hand dominancy. So, this $5 \mathrm{~mm}$ port was converted to a $10 \mathrm{~mm}$ port. After the complete resection, the gallbladder was extracted through the umbilical port. Total operative time was 60 minutes. Post-operative recovery was uneventful, and discharge was made on $4^{\text {th }}$ post-operative day.

\section{(1)}

\section{Discussion}

While there is no known association between SIT and Gall stone disease ${ }^{4-5}$, the clinical Diagnosis of gallstone disease cases of SIT is challenging and poses a dilemma for clinicians. The classical features of pain, including their location and nature are different. And imaging studies are required to make the diagnosis. In our case, ultrasonography was diagnostic, but in many cases a CT scan is used additionally, to confirm the diagnosis and rule out associated pathologies. Laparoscopic Cholecystectomy has been gold standard for treating gall stone disease worldwide. However, operating cases of SIT with Gall stones, where the mirror image orientation of viscera is totally different from most of the familiar anatomy, has tested surgeons skill and perseverance at the same time. Surgeons have to overcome the mental setup of organs position and plan for port sites, sizes, and instruments in order to co-ordinate both hands. In this case, attempt was made to mobilize and dissect the gall bladder keeping the working ports in epigastric and left subostal region. Hartmann's pouch retraction was tried through the epigastric port, but later working ports were switched to facilitate the surgeon's comfort. Clipping the cystic duct also required switching hands to use the dominant one, so ambidexterity may assist in completing these cases easily. 
Operating time was acceptable, and even shorter than some of the reported cases, but longer the average time required for a normal-portion gallbladder. This is related to the unfamiliarity with the anatomy, the need to use a modified technique and a need to think about each and every step of the procedure, even for a surgeon well versed in "normal" cholecystectomy. Naturally, firm conclusions cannot be drawn from this single case.

\section{Conclusion}

Although Laparoscopic Cholecystectomy is a widely practiced procedure for treating gall stone disease, cases with SIT demands highly skilled surgeons and a different theatre setup. The modification of the standard techniques should be made to conform to the surgeon's comfort and the actual anatomy. Longer operating time is expected due to the technical difficulties and the lack of familiarity with the reversed anatomy, but with an expert hand, this procedure can be completed safely.

\section{References}

1. Varano NR, Merkin RJ. Situs inversus: review of the literature, report of four cases and analysis of the clinical implications. J Int Coll Surg. 1960;33:131-5. [PubMed]

2. Damian McKay, Geoffrey Blake. Laparoscopic cholecystectomy in situs inversus totalis:a case report. BMC Surgery Mar 2005 DOI:10.1186/1471-2482- 5-5

3. Mhd Belal A, Shwaqi A, Alaa A. A case report of laparoscopic cholecystecomy in situs inversus totalis:Technique and anatomical variation. Int J Surg Case Report 2016; 28: 124-126.

4. Senthil K., Giuseppe Fusai. Laparoscopic Cholecystectomy in Situs Inversus totalis with Left sided Gall Bladder. Annals of the Royal College of Surgeons of England. 2007 April; 89(2):W16-W18.

5. Jian-Jun R, Shu-dong Li, Ya-jun G, Rui Xiao. Modified laparoscopic cholecystectomy technique for treatment of situs inversus totalis: a case report. Journal of international medical Research 2017,Vol.45(3)1261-1267 